\title{
Adrenoceptors of the medial septal area modulate water intake and renal excretory function induced by central administration of angiotensin II
}

\author{
W.A. Saad ${ }^{1,2}$, \\ I.F.M.S. Guarda ${ }^{3}$, \\ L.A.A. Camargo ${ }^{1}$, \\ T.A.F.B. Santos ${ }^{3}$, \\ S. Simões ${ }^{2}$ and \\ Willian A. Saad ${ }^{4}$
}

\author{
${ }^{1}$ Departamento de Fisiologia e Patologia, Faculdade de O dontologia, \\ Universidade Estadual Paulista, Araraquara, SP, Brasil \\ ${ }^{2}$ Departamento de O dontologia, U niversidade de Taubaté, Taubaté, SP, Brasil \\ 3Departamento de Anestesiologia, Hospital Médico 9 de Julho, São Paulo, SP, Brasil \\ ${ }^{4}$ Departamento de Cirurgia, Faculdade de Medicina, Universidade de São Paulo, \\ São Paulo, SP, Brasil
}

\author{
Correspondence \\ W.A. Saad \\ Departamento de Fisiologia e \\ Patologia \\ Faculdade de O dontologia, UNESP \\ Rua Humaitá, 1680 \\ 14801-903 Araraquara, SP \\ Brasil \\ Fax: + 55-16-201-6488 \\ E-mail: silvana@foar.unesp.br
}

Research supported by FAPESP, CNPq and FUNDUNESP.

Received February 8, 2001

Accepted June 11, 2002

\section{Abstract}

We investigated the role of $\alpha$-adrenergic antagonists and clonidine injected into the medial septal area (MSA) on water intake and the decrease in $\mathrm{Na}^{+}, \mathrm{K}^{+}$and urine elicited by ANGII injection into the third ventricle $(3 \mathrm{rdV})$. Male Holtzman rats with stainless steel cannulas implanted into the $3 \mathrm{rdV}$ and MSA were used. ANGII $(12 \mathrm{nmol} / \mu \mathrm{l})$ increased water intake $(12.5 \pm 1.7 \mathrm{ml} / 120 \mathrm{~min})$. Clonidine $(20 \mathrm{nmol} /$ $\mu l)$ injected into the MSA reduced the ANGII-induced water intake $(2.9 \pm 0.5 \mathrm{ml} / 120 \mathrm{~min})$. Pretreatment with $80 \mathrm{nmol} / \mu \mathrm{l}$ yohimbine or prazosin into the MSA also reduced the ANGII-induced water intake $(3.0 \pm 0.4$ and $3.1 \pm 0.2 \mathrm{ml} / 120 \mathrm{~min}$, respectively). Yohimbine + prazosin + clonidine injected into the MSA abolished the ANGIIinduced water intake $(0.2 \pm 0.1$ and $0.2 \pm 0.1 \mathrm{ml} / 120 \mathrm{~min}$, respectively). ANGII reduced $\mathrm{Na}^{+}(23 \pm 7 \mu \mathrm{Eq} / 120 \mathrm{~min}), \mathrm{K}^{+}(27 \pm 3 \mu \mathrm{Eq} / 120$ $\mathrm{min})$ and urine volume $(4.3 \pm 0.9 \mathrm{ml} / 120 \mathrm{~min})$. Clonidine increased the parameters above. Clonidine injected into the MSA abolished the inhibitory effect of ANGII on urinary sodium. Yohimbine injected into the MSA also abolished the inhibitory effects of ANGII. Yohimbine + clonidine attenuated the inhibitory effects of ANGII. Prazosin injected into the MSA did not cause changes in ANGII responses. Prazosin + clonidine attenuated the inhibitory effects of ANGII. The results showed that MSA injections of $\alpha_{1^{-}}$and $\alpha_{2}$-antagonists decreased ANGII-induced water intake, and abolished the $\mathrm{Na}^{+}, \mathrm{K}^{+}$and urine decrease induced by ANGII into the $3 \mathrm{rdV}$. These findings suggest the involvement of septal $\alpha_{1}$ - and $\alpha_{2}$-adrenergic receptors in water intake and electrolyte and urine excretion induced by central ANGII.

\section{Key words}

- $\alpha$-Adrenoceptors

- Angiotensin II

- Water intake

- Sodium

- Potassium

- W ater excretion

- Medial septal area 


\section{Introduction}

Central administration of angiotensin II (ANGII) induces thirst in satiated animals by interacting with neurotransmitters, especially catecholamines $(1,2)$. Adrenergic neurotransmitters from several hypothalamic areas may participate in the effect of ANGII regulating hydromineral fluid intake and renal electrolyte excretion in a process that involves $\alpha_{1}$ and $\alpha_{2}$-adrenoceptors (3-5). Central injection of an $\alpha$-adrenergic antagonist suppresses water intake induced by intracerebroventricular (icv) ANGII $(6,7)$. Several areas of the limbic system participate in the regulation of sodium, potassium and water excretion (8). Previous studies have demonstrated the effects of $\alpha$-antagonists and agonists injected into the lateral hypothalamus on the water and sodium intake induced by ANGII injection into the subfornical organ (3). The adrenergic pathways of the septal area play an important role in the regulation of electrolyte and water excretion. $\alpha$-Adrenoceptors present an excitatory effect, whereas $\beta$-adrenoceptors present an inhibitory effect $(9,10)$. Rats with electrolytic lesions of the septal area drink more water than normal ones in response to thirst stimuli mediated by ANGII (11). Extensive neural pathways from circumventricular structures to the septal area are involved in the regulation of fluid intake and cardiovascular regulation $(12,13)$. Clonidine, an $\alpha_{2}$-adrenergic receptor agonist, has a potent and well-known antidipsogenic action (14-17). Peripheral or central injection of clonidine reduces water intake induced by peripheral or central administration of ANGII $(18,19)$. Central treatment with yohimbine (an $\alpha_{2}$-adrenergic receptor antagonist) reduces the antidipsogenic effect of clonidine, suggesting the participation of $\alpha_{2}$-adrenergic receptors in this effect (18). Idazoxan (an $\alpha_{2}$-adrenergic and imidazoline receptor antagonist) reduced the effect of clonidine on hypertonic $\mathrm{NaCl}$ and water intake (20). The natriuretic-kaliuretic response elicited by cholinergic stimulation of the lateral hypothalamic area depends in part on synapses located in the medial septal area (MSA), the response elicited by cholinergic stimulation of the MSA also utilizes synapses located in the lateral hypothalamic area (21). Increased renal sodium and potassium excretion has been obtained with noradrenaline and other adrenergic drugs injected into the septal area (9). There is some evidence that fibers from the subfornical organ converge to the nucleus medianus and also project to the supraoptic nucleus, paraventricular nucleus and throughout the lateral preoptic area-lateral hypothalamic area (22). The central part of the subfornical organ, which is linked to circulating ANGII (23), also contains ANGII-immunoreactive terminal fields which seem to come from cells in the MSA (24). In view of the importance of the circumventricular structures and MSA for the hydromineral balance in rats $(9,25)$, as well as the important interactions between areas of the circumventricular structures and the MSA, we determined the effect of the injection of clonidine, yohimbine and prazosin into the MSA on water intake and on the antinatriuretic, antikaliuretic and antidiuretic effects induced by the administration of ANGII into the third ventricle $(3 \mathrm{rdV})$.

\section{Material and Methods}

\section{Animals}

Male Holtzman rats weighing 240-280 g at the beginning of the experiments were housed in individual metabolic cages. Standard Purina pellets $\left(\mathrm{Na}^{+}\right.$content $5 \mathrm{nmol} / 100$ g) and tap water were available ad libitum. The temperature in the animal colony was maintained at approximately $23^{\circ} \mathrm{C}$. The $12 /$ 12-h light-dark cycle began with lights on at 8:00 am. All animals used in the experiments received the same drugs but at different times. However, each animal was used 
in four experiments at most.

\section{Brain surgery}

After an acclimatization period of 7 days, the animals were restrained in a stereotaxic apparatus (Kopf model) and maintained under intraperitoneal tribromoethanol $(20 \mathrm{mg} /$ $100 \mathrm{~g}$ body weight; Aldrich Chemical Company Inc., Milwaukee, WI, USA) anesthesia throughout surgery. A longitudinal incision was made in the skin of the head of each animal, the subcutaneous tissue was pulled back and the skull was drilled with a spherical drill. A stainless steel cannula (14 x 0.7 mm OD) was introduced into the MSA and another cannula (10 x $0.7 \mathrm{~mm}$ OD) was introduced into the $3 \mathrm{rdV}$. The skull was positioned by having the bregma and lambda at the same level. The coordinates for approaching the MSA and $3 \mathrm{rdV}$ were obtained from the Paxinos and Watson atlas (26). For the MSA the following coordinates were used: AP, $0.9 \mathrm{~mm}$ caudal to the bregma; $\mathrm{L}$, $0.0 \mathrm{~mm}$ in the midline, and $\mathrm{V}, 4.6 \mathrm{~mm}$ below the dura mater. For the $3 \mathrm{rdV}$, the following coordinates were used: AP, $0.2 \mathrm{~mm}$ caudal to bregma; $\mathrm{L}, 0.0 \mathrm{~mm}$ on the sagittal line, and $\mathrm{V}, 7.8 \mathrm{~mm}$ below the dura mater. The cannula was fixed to the skull with screws and acrylic resin. A prophylactic dose of penicillin (30,000 IU) (Pentabiótico, Fontoura Wyeth, São Paulo, SP, Brazil) was given intramuscularly and presurgically. The insertion of a close-fitting stylet kept the lumen free of debris and clots.

\section{Intracerebral injection techniques}

Bolus intracranial injections were made after gently removing the animal from its cage, replacing the stylet with an injector that protruded $1.0 \mathrm{~mm}$ beyond the tip of the guide cannula in order to reach the MSA and $3 \mathrm{rdV}$. This injector was connected by a PE10 tubing to a $10-\mu l$ microsyringe, and a total volume of $1.0 \mu \mathrm{l}$ was injected over a period of 30-60 s. The stylet and injector were constantly wiped with cotton soaked in $70 \%$ alcohol. After the injection, the injector was removed, the stylet was replaced and the animals were returned to their cages so that we could observe the water intake, as well as renal sodium, potassium and water excretion.

\section{Drugs}

The drugs were dissolved in sterile 0.15 $\mathrm{M} \mathrm{NaCl}$ and injected into the MSA or $3 \mathrm{rdV}$ with a Hamilton microsyringe $(10 \mu \mathrm{l})$ connected by PE-10 polyethylene tubing ( 25 $\mathrm{cm})$ to a needle (0.3 $\mathrm{mm} \mathrm{OD})$, and introduced into the brain through the cannula previously fixed to the animals' heads. The volume of injection was always $1 \mu \mathrm{l}$ injected over a 30-60-s period.

The drugs used were clonidine hydrochloride (Boehringer-Ingelheim Ltd., London, UK), prazosin hydrochloride (Pfizer, Guarulhos, SP, Brazil), yohimbine hydrochloride (Sigma, St. Louis, MO, USA), and Ile ${ }^{5}$-angiotensin II (Sigma). Saline (0.15 M $\mathrm{NaCl}$ ) was used as control.

\section{Histology}

After the experiments, the animals were anesthetized with ether and perfused through the heart with saline and $10 \%$ formalin. The brain was removed and stored in $10 \%$ formalin for at least 1 week. It was then frozen and coronal sections $(20-30 \mu \mathrm{m})$ were cut and stained with hematoxylin-eosin for examination by light microscopy. Only the results of rats whose MSA and $3 \mathrm{rdV}$ were reached by the injection were used. Figure $1 \mathrm{~A}$ and $\mathrm{B}$ shows the site of injection into the MSA and $3 \mathrm{rdV}$ as indicated by the arrows.

\section{Statistical analysis}

Data are reported as means \pm SEM and were analyzed by one-way analysis of vari- 
ance. Values were considered to be statistically significant when $\mathrm{P}<0.05$. The Newman-Keuls post hoc test was used to assess the difference between individual means.

\section{Experimental protocol}

The study of water ingestion, as well as renal sodium, potassium and water excretion produced by injecting ANGII into the $3 \mathrm{rdV}$ was started 5 days after brain surgery. Water ingestion and the renal parameters were determined during different experimental sessions and in several groups of animals after the injection of the following drugs into the MSA and 3rdV of satiated rats: saline into the MSA and 3rdV (control); saline into the MSA and ANGII (12 nmol) into the $3 \mathrm{rdV}$; clonidine $(20 \mathrm{nmol})$ or yohimbine or prazo$\sin (80 \mathrm{nmol})$ into the MSA and saline into the $3 \mathrm{rdV}$; clonidine (20 $\mathrm{nmol}$ ) or yohimbine or prazosin $(80 \mathrm{nmol})$ into the MSA and ANGII into the $3 \mathrm{rdV}$; yohimbine or prazosin $(80 \mathrm{nmol})+$ clonidine $(20 \mathrm{nmol})$ into the MSA and ANGII (12 nmol) into the 3rdV.

Figure 1. Photomicrographs of a hematoxylin-eosin-stained transverse section of the rat brain showing the sites (arrows) of injection into the medial septal area $(A)$ and into the third ventricle (B).
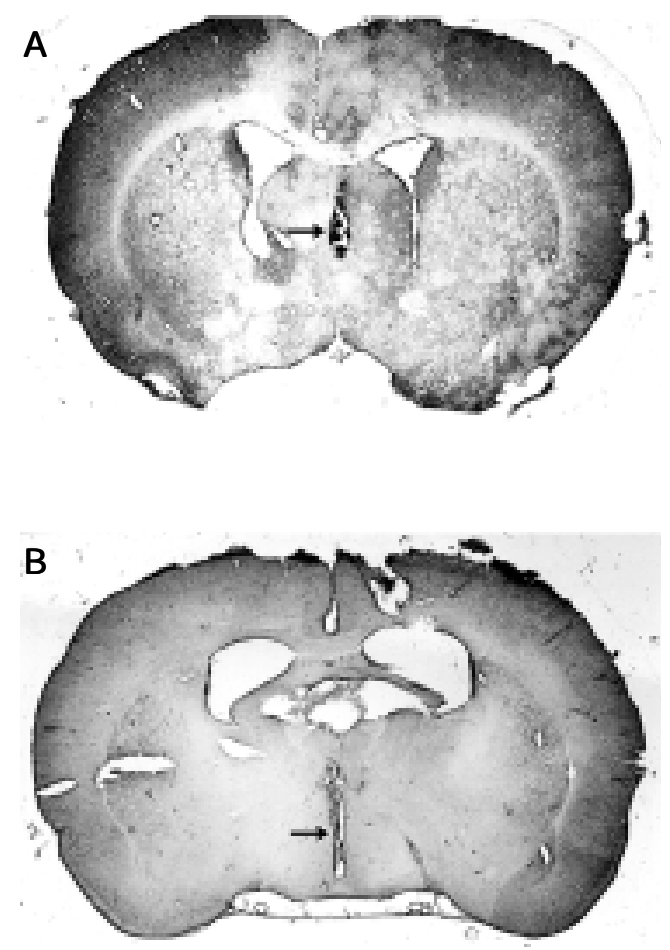

Water intake was recorded for $2 \mathrm{~h}$ after the injection of ANGII into the $3 \mathrm{rdV}$. Prazosin and yohimbine were also injected $20 \mathrm{~min}$ before ANGII. When associated with clonidine, prazosin and yohimbine were injected $20 \mathrm{~min}$ before clonidine. The volume of water was measured using graduated $(0.1 \mathrm{ml}$ markings) tubes fitted with metal drinking spouts. No solid food was made available to the animals during the experiments.

Urine was collected after a period of solid food deprivation, and the animals were weighed and received a $5 \%$ water overload by gavage, consisting of a volume of water at $37^{\circ} \mathrm{C}$ equal to their body weight. The animals were returned to their cages, with no water or solid food available. Excreted urine was collected into graduated tubes through a funnel located at the bottom of the cage. After 60 min the rats were submitted to a second water overload ( $5 \%$ of body weight) by gavage. Twenty minutes later, a control urine sample was collected and the drug was diluted in $1 \mu 10.15 \mathrm{M} \mathrm{NaCl}$ solution and injected into the MSA/3rdV. Urine samples were collected $2 \mathrm{~h}$ after this injection. Sodium and potassium concentrations in the urine samples were measured with an IL-143 flame spectrophotometer (Instrumental Laboratories, Lexington, MA, USA).

\section{Results}

Effect of pretreatment with intraseptal yohimbine and prazosin on the water intake induced by ANGII injected into the 3rdV

The injection of ANGII $(12 \mathrm{nmol})$ into the $3 \mathrm{rdV}$ produced a progressive increase in water intake starting $30 \mathrm{~min}$ after injection. After injection of $0.15 \mathrm{M} \mathrm{NaCl}$ (control) into the MSA/3rdV, water intake was $0.4 \pm 0.1$ $\mathrm{ml} / 120 \mathrm{~min}$. The injection of ANGII into the $3 \mathrm{rdV}$ produced an increase in water intake to $12.5 \pm 1.7 \mathrm{ml} / 120 \mathrm{~min}$. Clonidine (20 nmol) injection into the MSA before ANGII injec- 
tion into the $3 \mathrm{rdV}$ decreased water intake to $2.9 \pm 0.5 \mathrm{ml} / 120 \mathrm{~min}$. Yohimbine $(80 \mathrm{nmol})$ and prazosin $(80 \mathrm{nmol})$ injected into the MSA before injection of ANGII into the $3 \mathrm{rdV}$ decreased the dipsogenic effect of ANGII, with water intake of $3.0 \pm 0.4$ and $3.1 \pm 0.2 \mathrm{ml} / 120 \mathrm{~min}$, respectively. Yohimbine and prazosin injected before clonidine into the MSA, and before injection of ANGII into the $3 \mathrm{rdV}$ abolished the effect of ANGII, reducing water intake to control values, i.e., $0.2 \pm 0.1$ and $0.2 \pm 0.1 \mathrm{ml} / 120 \mathrm{~min}$, respectively (Figure 2).

\section{Effect of the injection of yohimbine or prazosin before clonidine into the MSA on renal sodium excretion after the administration of ANGII into the 3rdV}

Injection of $0.15 \mathrm{M} \mathrm{NaCl}$ into the MSA/ $3 \mathrm{rdV}$ induced a urinary sodium excretion of $129 \pm 27 \mu \mathrm{Eq} / 120 \mathrm{~min}$. Intracerebroventricular ANGII reduced sodium excretion to $23 \pm 7.0 \mu \mathrm{Eq} / 120 \mathrm{~min}$. Clonidine injected into the MSA increased sodium excretion to $246 \pm 14 \mu \mathrm{Eq} / 120 \mathrm{~min}$. Treatment with clonidine into the MSA reduced the inhibitory effect of ANGII on sodium excretion (179 \pm $27 \mu \mathrm{Eq} / 120 \mathrm{~min}$ ). Sodium excretion after yohimbine administration into the MSA was $123 \pm 11 \mu \mathrm{Eq} / 120 \mathrm{~min}$. Treatment with yohimbine attenuated the inhibitory effect of ANGII on renal sodium excretion $(103 \pm 16$ $\mu \mathrm{Eq} / 120 \mathrm{~min}$ ). Sodium excretion after prazosin injection into the MSA was $125 \pm 12$ $\mu E q / 120$ min. Prazosin produced no significant change in the inhibitory effect of ANGII on sodium excretion (14 $\pm 2 \mu \mathrm{Eq} / 120 \mathrm{~min})$. Treatment with yohimbine before clonidine and ANGII attenuated the decrease in sodium excretion induced by ANGII, but with less intensity compared to clonidine injected before ANGII, with values of $59 \pm 8 \mu \mathrm{Eq} /$ 120 min. Treatment with prazosin before clonidine and ANGII produced no significant change in sodium excretion $(33 \pm 8$ $\mu \mathrm{Eq} / 120$ min) (Figure 3).

\section{Effect of the injection of yohimbine or prazosin before clonidine into the MSA on renal potassium excretion after the application of ANGII into the 3rdV}

Potassium excretion after injection of $0.15 \mathrm{M} \mathrm{NaCl}$ into the MSA/3rdV was $101 \pm$ $12 \mu \mathrm{Eq} / 120 \mathrm{~min}$. ANGII injected into the $3 \mathrm{rdV}$ caused a reduction in renal potassium excretion to $27 \pm 3 \mu \mathrm{Eq} / 120 \mathrm{~min}$. Treatment with clonidine into the MSA increased potassium excretion $(191 \pm 15 \mu \mathrm{Eq} / 120 \mathrm{~min})$. Intraseptal clonidine reduced icv ANGIIinhibited potassium excretion $(117 \pm 5 \mu \mathrm{Eq} /$ $120 \mathrm{~min}$ ). Potassium excretion after yohim-
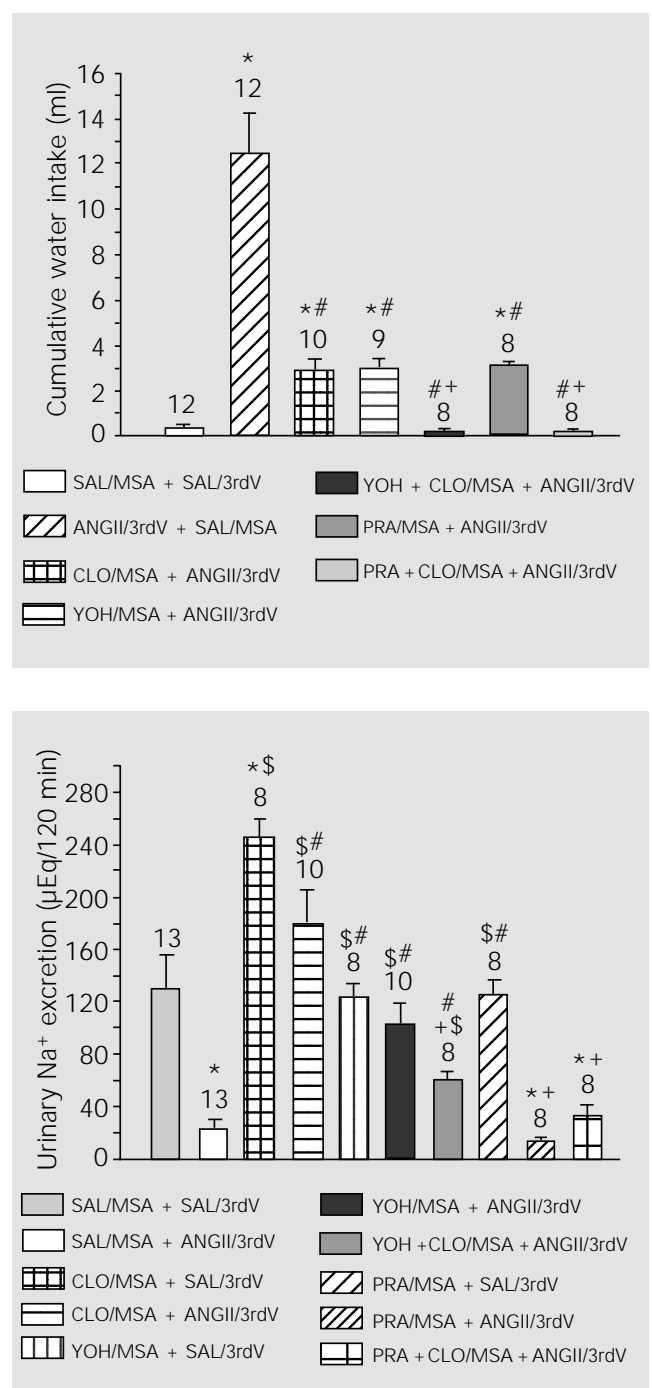

Figure 2. Cumulative water intake induced by intracerebroventricular injection of angiotensin II (ANGII, $12 \mathrm{nmol} / \mu \mathrm{l}$ ) in rats treated with intraseptal injection of clonidine (CLO, $20 \mathrm{nmol} / \mathrm{\mu l})$, yohimbine $(\mathrm{YOH}, 80 \mathrm{nmol} / \mathrm{\mu l})$ or prazosin (PRA, $80 \mathrm{nmol} / \mathrm{\mu l})$. The number of animals is indicated at the top of each column. The results are reported as means \pm SEM. $* P<0.05$ compared to SAL/MSA + SAL/3rdV. \#P $<0.05$ compared to SAL/MSA + ANGII/ 3rdV. ${ }^{+} \mathrm{P}<0.05$ compared to CLO/MSA + ANGII/3rdV (Newman-Keuls post hoc test). SAL, saline; MSA, medial septal area; 3rdV, third ventricle.

Figure 3. Urinary sodium excretion induced by intracerebroventricular injection of angiotensin II (ANGIl, $12 \mathrm{nmol} / \mu \mathrm{l}$ ) into the third ventricle (3rdV) of rats treated with intraseptal clonidine (CLO, $20 \mathrm{nmol} / \mathrm{\mu l})$, yohimbine $(\mathrm{YOH}, 80$ $\mathrm{nmol} / \mathrm{\mu l}$ ) or prazosin (PRA, 80 $\mathrm{nmol} / \mu \mathrm{ll})$. The results are reported as means \pm SEM. The number of animals is indicated at the top of each column. $* \mathrm{P}<0.05$ compared to SAL/MSA + SAL/3rdV. \#P $<0.05$ compared to CLO/MSA + SAL/3rdV. \$P<0.05 compared to SAL/MSA + ANGII/3rdV. $+P<0.05$ compared to CLO/MSA + ANGII/3rdV (Newman-Keuls post hoc test). SAL, saline; MSA, medial septal area. 
bine injection into the MSA was $106 \pm 16$ $\mu \mathrm{Eq} / 120 \mathrm{~min}$. The decrease in renal potassium excretion after ANGII injection into the $3 \mathrm{rdV}$ was attenuated by yohimbine, with values of $91 \pm 11 \mu \mathrm{Eq} / 120 \mathrm{~min}$. Yohimbine injected before clonidine and ANGII attenuated potassium excretion $(52 \pm 11 \mu \mathrm{Eq} / 120$ min). Potassium excretion after treatment with prazosin was $32 \pm 7 \mu \mathrm{Eq} / 120 \mathrm{~min}$. Prazosin produced no change in the inhibitory effect of ANGII on renal potassium excretion (24 $\pm 6 \mu \mathrm{Eq} / 120 \mathrm{~min})$. Potassium excretion after treatment with prazosin injected before clonidine and ANGII was

Figure 4. Urinary potassium excretion induced by intracerebroventricular injection of angiotensin II (ANGII, $12 \mathrm{nmol} / \mu \mathrm{ll}$ ) into the third ventricle (3rdV) of rats treated with intraseptal clonidine $(\mathrm{CLO}, 20 \mathrm{nmol} / \mathrm{\mu l})$, yohimbine $(\mathrm{YOH}, 80 \mathrm{nmol} / \mathrm{\mu l})$ or prazosin (PRA, $80 \mathrm{nmol} / \mathrm{\mu l}$ ). The number of animals is indicated at the top of each column. The results are reported as means \pm SEM. $* \mathrm{P}<0.05$ compared to SAL/MSA + SAL/3rdV. \#P<0.05 compared to $\mathrm{CLO} / \mathrm{MSA}+\mathrm{SAL} / 3 \mathrm{rdV}$. $\$ \mathrm{P}<0.05$ compared to SAL/MSA + ANGII/3rdV. $+P<0.05$ compared to CLO/MSA + ANGII/ 3rdV (Newman-Keuls post hoc test). SAL, saline; MSA, medial septal area.

Figure 5. Urinary volume excretion induced by intracerebroventricular injection of angiotensin II (ANGII, $12 \mathrm{nmol} / \mathrm{\mu l}$ ) into the third ventricle (3rdV) of rats treated with intraseptal clonidine (CLO, $20 \mathrm{nmol} / \mu \mathrm{l})$, yohimbine $(\mathrm{YOH}, 80$ $\mathrm{nmol} / \mu \mathrm{l}$ ) or prazosin (PRA, 80 $\mathrm{nmol} / \mu \mathrm{l})$. The results are reported as means $\pm \mathrm{SEM}$. The number of animals is indicated at the top of each column. *P $<0.05$ compared to SAL/MSA + SAL/3rdV. \#P $<0.05$ compared to CLO/MSA + SAL/3rdV. \$P $<0.05$ compared to SAL/MSA + ANGII/3rdV. $+\mathrm{P}<0.05$ compared to CLO/MSA + ANGII/3rdV (Newman-Keuls post hoc test). SAL, saline; MSA, medial septal area.
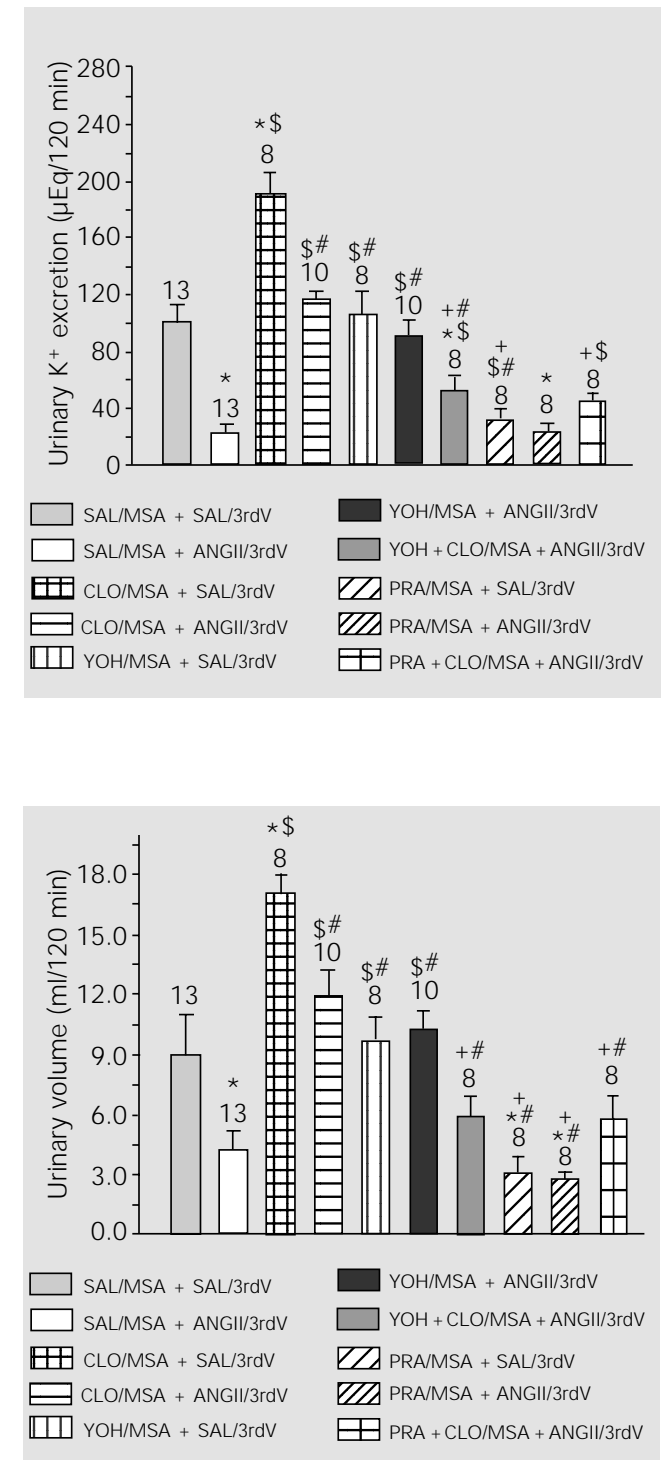

$45 \pm 6 \mu \mathrm{Eq} / 120 \min$ (Figure 4).

\section{Effect of the injection of yohimbine or prazosin before clonidine into the MSA on urine volume after injection of ANGII into the 3rdV}

Urine volume after injection of $0.15 \mathrm{M}$ $\mathrm{NaCl}$ into the MSA $/ 3 \mathrm{rdV}$ was $9.0 \pm 2.0 \mathrm{ml} /$ $120 \mathrm{~min}$. ANGII injected into the $3 \mathrm{rdV}$ caused a reduction of urine volume to $4.3 \pm 0.9 \mathrm{ml} /$ $120 \mathrm{~min}$. Treatment with clonidine into the MSA increased urine volume to $17.1 \pm 0.9$ $\mathrm{ml} / 120 \mathrm{~min}$. Clonidine abolished the inhibitory effect of ANGII on urine volume (11.9 \pm $1.3 \mathrm{ml} / 120 \mathrm{~min})$. Urine volume after intraseptal treatment with yohimbine was $9.7 \pm 1.2 \mathrm{ml} / 120 \mathrm{~min}$. Yohimbine attenuated the reduction of urine volume caused by ANGII (10.3 $\pm 0.9 \mathrm{ml} / 120 \mathrm{~min})$. Yohimbine injected before clonidine and ANGII abolished the effect of clonidine on urine volume $(5.9 \pm 1.0 \mathrm{ml} / 120 \mathrm{~min})$. The urine volume after intraseptal prazosin was $3.1 \pm 0.8 \mathrm{ml} /$ $120 \mathrm{~min}$. Prazosin produced no change in the urine volume caused by ANGII $(2.8 \pm 0.3$ $\mathrm{ml} / 120 \mathrm{~min}$ ). Prazosin injected before clonidine and ANGII abolished the effect of clonidine on urine volume $(5.8 \pm 1.1 \mathrm{ml} / 120$ min) (Figure 5).

\section{Discussion}

The present results show that the $\alpha_{2}$ adrenoceptor agonist clonidine injected into the MSA attenuated the dipsogenic response produced by ANGII injection into the $3 \mathrm{rdV}$. Prior injection of the $\alpha_{1}$ - and $\alpha_{2}$-adrenergic receptor antagonists, prazosin and yohimbine, into the MSA reduced the icv ANGIIinduced water intake. However, it has been shown that central treatment with an adrenergic agent also increases the water intake induced by ANGII in rats (5). Prazosin and phentolamine injected into the rostral hypothalamus attenuate the drinking response induced by icv ANGII injection (6). Thus, the 
inhibitory and facilitatory effects of noradrenaline injected into the central nervous system on ingestive behavior suggest a dual role for noradrenaline in the central control of water and salt intake induced by ANGII (27). The present results also show that ANGII injection into the $3 \mathrm{rdV}$ decreased sodium, potassium and water excretion in water-loaded rats. Injection of clonidine into the MSA abolished the antinatriuresis, antikaliuresis and antidiuresis induced by ANGII injected into the $3 \mathrm{rdV}$. The decrease in sodium, potassium and water excretion induced by ANGII injection into the $3 \mathrm{rdV}$ in waterloaded rats (with volume expansion) was abolished by pretreatment with yohimbine injected into the MSA. Although several studies have shown the natriuretic effect of ANGII, the present results showed the antinatriuretic effect of ANGII injected into the $3 \mathrm{rdV}$. Intracerebroventricular injection of ANGII produced a decrease in sodium excretion. The different effects of ANGII on natriuresis suggest that central control of natriuresis may involve more than one mechanism depending on the excitatory stimuli that activate different areas of the central nervous system. Urine volume was also reduced by $i c v$ administration of ANGII (28). Other studies have demonstrated several interactions between adrenergic, cholinergic and angiotensinergic pathways in the central nervous system (3). Adrenergic stimulation of the MSA influences sodium and potassium excretion (29). Natriuresis resulting from $\alpha_{2}$-adrenoceptor activation has been demonstrated by the application of noradrenaline, clonidine, but not phenylephrine (30). The same occurs with injection of adrenergic agonists or antagonists into the MSA on the renal excretory function response to icv ANGII. Taken together, these results show that the central injection of an $\alpha$-adrenergic agonist or antagonist can disrupt the renal effect of ANGII in rats and suggest that the adrenergic pathways of the MSA can produce a dual effect on electrolyte excretion.
Clonidine induced an increase in sodium, potassium and water excretion which was reduced by treatment with yohimbine and prazosin by blocking the $\alpha_{2}$-adrenoceptor subtype. The release of norepinephrine may be an excitatory step along the ANGIIinduced sodium, potassium and water excretion pathway and when an adrenergic antagonist is used it can block these responses. In spite of this excitatory effect, the adrenergic pathways could also be involved in an inhibitory system for electrolyte and water excretion. The participation of the lateral hypothalamic area in these mechanisms of water intake was also demonstrated (21). The autoradiographic localization of [3]clonidine binding to non-adrenergic sites was similar to, but distinct from, $\alpha_{2}$-adrenergic receptors in human brain (31). Prazosin is effective in blocking the natriuretic and kaliuretic response to the $\alpha_{1}$-adrenoceptor agonist phenylephrine (32). The present study shows that injection of prazosin into the MSA did not modify the inhibitory responses induced by ANGII injected into the $3 \mathrm{rdV}$ on sodium, potassium and water excretion. Clonidine induced natriuresis, kaliuresis and diuresis when injected into the MSA. Evidence has shown that clonidine, when centrally injected alone, produces diuresis, kaliuresis and natriuresis (33-35). The diuresis produced by the central administration of clonidine has been attributed to the inhibition of vasopressin release (35) and natriuresis has been attributed to renal sympathoinhibition $(34,36)$. The present results suggest that the facilitatory effect of clonidine on natriuresis and kaliuresis is mediated by the activation of $\alpha_{1}$-adrenoceptors and the inhibitory effects are mediated by $\alpha_{2 \mathrm{~A}}$-adrenoceptors (37). Circumventricular structures present excitatory and inhibitory mechanisms responsible for regulating the renal sodium, potassium and water excretion (29). The adrenergic neurotransmission in the median preoptic nucleus may actively participate in ANGII-induced dipsogenesis, di- 
uresis, kaliuresis, and pressor responses in a process that involves $\alpha_{1}$ - and $\alpha_{2}$-adrenoceptors (38). Thus, the $\alpha_{2}$-receptors of the MSA play an inhibitory role and the $\alpha_{1}$-receptors play an excitatory role in sodium, potassium and water excretion. Another important fact is that the effect of $\alpha_{1}$ - and $\alpha_{2}$-adrenoceptors on ANGII, which affects water and electrolyte regulation, is due to the release or inhibition of vasopressin or atrial natriuretic factor. The administration of clonidine has been reported to increase the circulating levels of atrial natriuretic factor (29). Vasopressin or atrial natriuretic factor has some influence on sodium, potassium and water.

The participation of imidazoline receptors in the effect of $\alpha_{2}$-adrenoceptors has been postulated. It has been demonstrated that rilmenidine, an imidazoline agonist, when injected into the paraventricular nucleus of the hypothalamus, decreases the hypertensive effect of ANGII injected into the $3 \mathrm{rdV}$ (39). It has also been observed that rilmenidine injection into the paraventricular nucleus of the hypothalamus, prior to ANGII injection into the subfornical organ blocks the dipsogenic effect of ANGII (33).
These observations support the notion that yohimbine reversed the effect of ANGII when injected alone by blocking the imidazoline receptors. ANGII may produce antinatriuresis, antikaliuresis and antidiuresis by acting on imidazoline receptors. This response was confirmed by yohimbine blocking the clonidine effect. Yohimbine injected with clonidine failed to fully reverse the effect of ANGII, probably due to the action of clonidine on the imidazoline receptors. These findings agree with the results of other studies reporting that imidazoline drugs such as clonidine, rilmenidine and the catecholamine $\alpha_{2}$-adrenoceptor agonist $\alpha$-methylnorepinephrine have distinct mechanisms of action (40).

\section{Acknowledgments}

The authors thank José Vanderlei Menani and Laurival Antonio de Luca Jr. for helping to improve the manuscript. They also appreciate the technical assistance of Reginaldo C. Queiróz, Silas P. Barbosa, Silvana A.D. Malavolta and Silvia Foglia. We would also like to thank Ana V. Oliveira for animal care.

\section{References}

1. Epstein AN, Fitzsimons JY \& Rolls BJ (1970). Drinking induced by injection of angiotensin into the brain of the rat. J ournal of Physiology, 210: 457-474.

2. Summers C (1992). Norepinephrine increases angiotensin II binding in the rat synaptosomes. Brain Research Bulletin, 28: 411-415.

3. Almeida NAA, Antunes VR, Saad WA \& Camargo LAA (1999). Effects of alpha antagonists and agonists injected into lateral hypothalamus on the water and sodium intake induced by angiotensin II injection into the subfornical organ. Brain Research Bulletin, 48: 521-525.

4. Bastos R, Saad WA, Menani J V, Renzi A, Silveira J EN \& Camargo LAA (1994). Role of adrenergic pathway of the medial preoptic area in ANG II-induced water and renal excretion in rats. Brain Research, 636: 81-86.
5. Chan JYH, Pan S \& Chan SHH (1991). Participation of adrenergic neurotransmission in angiotensin II-induced dipsogenic behavior in the rat. Life Sciences, 48 : 1293-1301.

6. Jones DL (1988). Hypothalamic alphaadrenergic blockade modifies drinking and blood pressure responses to central angiotensin II in conscious rats. Canadian J ournal of Physiology and Pharmacology, 66: 1270-1277.

7. Severs WB, Summy-Long J, DanilsSevers A \& Connor JD (1971). Influence of adrenergic blocking drugs on central angiotensin effects. Pharmacology, 5: 205-214.

8. Pillar AX, Silva-Netto CR, Camargo LAA, Saad WA, Antunes Rodrigues J \& Covian MR (1977). Adrenergic stimulation of the lateral hypothalamic area on sodium and potassium excretion. Pharmacology, Bio- chemistry and Behavior, 6: 147-149.

9. Camargo LAA, Saad WA, Silva-Netto CR, Gentil CG, Antunes-Rodriques J \& Covian MR (1976). Effects of catecholamines injected into the septal area of the rat brain on natriuresis, kaliuresis and diuresis. $\mathrm{Ca}$ nadian J ournal of Pharmacology, 54: 219228.

10. Rocha MJA, Franci CR \& AntunesRodrigues J (1985). Participation of cholinergic and adrenergic synapses of the medial septal area (MAS) in the natriuretic, kaliuretic and diuretic response to intraventricular hypertonic saline $(\mathrm{NaCl})$. Physiology and Behavior, 34: 23-28.

11. Blass EM, Nussbaum IA \& Hanson DG (1974). Septal hyperdipsia: Specific enhancement of drinking to angiotensin in rats. J ournal of Comparative and Physiological Psychology, 87: 422-439.

12. Luis AC, Saad WA, Camargo LAA, Renzi 
A, De Luca J r LA \& Menani JV (1991). Pressor, natriuretic and kaliuretic response to central carbachol in rats with lesion of the medial septal area. Neuroscience Letters, 132: 195-198.

13. Saad WA, Antunes-Rodrigues J , Gentil CG \& Covian MR (1972). Interaction between hypothalamus, amygdala and septal area in the control of sodium chloride intake. Physiology and Behavior, 9: 629-636.

14. Callera J C, Camargo LAA, De Luca J r LA, Menani J V, Renzi A \& Saad WA (1993). Clonidine and phenylephrine injected into the lateral preoptic area reduce water intake in dehydrated rats. J ournal of Pharmacology and Experimental Therapeutics, 46: 39-43.

15. Callera J C, Saad WA, Camargo LAA, Renzi A, De Luca J r LA \& Menani JV (1994). Role of the adrenergic pathways of the lateral hypothalamus on water intake and pressor response induced by the cholinergic activation of the medial septal area in rats. Neuroscience Letters, 167: 153155.

16. Colombari E, Saad WA, Camargo LAA, Renzi A, De Luca J $r$ LA \& Menani JV (1990). Role of the central $\alpha_{1}$ and $\alpha_{2^{-}}$ adrenoceptors on the dipsogenic and cardiovascular effect of angiotensin II. Pharmacology, Biochemistry, and Behavior, 36: 893-896.

17. Ferrari AC, Camargo LAA, Saad WA, Renzi A, De Luca J r LA \& Menani JV (1991). Role of the alpha1- and alpha2-adrenoceptors of the lateral hypothalamus in the dipsogenic response to central angiotensin II in rat. Brain Research, 560: 291296.

18. Fregly MJ, Rowland $N \&$ Greenleaf JE (1984). A role for presynaptic $\alpha_{2}$-adrenoceptors in angiotensin II-induced drinking in rats. Brain Research Bulletin, 12: 393398.

19. Fregly MJ, Rowland N \& Greenleaf JE (1984). Clonidine antagonist of angiotensin-related drinking: A central site of action. Brain Research, 298: 321-327.

20. Yada MM, De Paula PM, Menani J V, Renzi A, Camargo LAA, Saad WA \& De Luca J r LA (1997). Receptor-mediated effects of clonidine on need-induced $3 \% \mathrm{NaCl}$ and water intake. Brain Research Bulletin, 42: 205-209.

21. Franci CR, Silva-Netto CR, Saad WA, Camargo LAA \& Antunes-Rodrigues J (1980). Interaction between the lateral hypotha- lamic area (LHA) and the medial septal area (MAS) in the control of sodium and potassium excretion in rats. Physiology and Behavior, 25: 801-806.

22. Thrasher TN (1989). Role of the forebrain circumventricular organs in body fluid balance. Acta Physiologica Scandinavica, 583 (Suppl): 141-150.

23. Van Houtten $M$, Schiffrin EL, Mann J FE, Posner BI \& Boucher R (1980). Radioautographic localization of specific binding sites for blood bom angiotensin II in rat brain. Brain Research, 186: 480-485.

24. Saad WA, Camargo LAA \& Simões $S$ (1998). Effect of electrolytic and chemical lesion by ibotenic acid of the septal area on water and salt intake. Brain Research Bulletin, 47: 163-169.

25. Camargo LAA, Menani J V, Saad WA \& Saad WA (1984). Interaction between areas of the central nervous system in the control of water and arterial pressure in rats. J ournal of Physiology, 350: 1-8.

26. Paxinos $G \&$ Watson $C$ (1986). The Rat Brain in Stereotaxic Coordinates Atlas. Academic Press, San Diego, CA, USA.

27. De Luca J r LA, Camargo LAA, Menani J V, Renzi A \& Saad WA (1994). On a possible dual role for central noradrenaline in the control of hydromineral fluid intake. Brazilian J ournal of Medical and Biological Research, 27: 905-914.

28. Thunhorst RL \& J ohnson AK (1993). Effects of arterial pressure on drinking and urinary responses to intracerebroventricular angiotensin II. American J ournal of Physiology, 264: R211-R217.

29. Saad WA, Guarda IFMS, Ferreira AC, Camargo LAA, Neto AFS, Santos TAFB \& Saad WA (2000). Participation of alpha-1 and alpha-2 adrenoceptors of the hypothalamic area in water intake, and renal sodium, potassium and urinary volume excretion induced by central administration of angiotensin II. Brain Research Bulletin, 52: 491-497.

30. Leite DF, Camargo LAA, Saad WA, Renzi A, Foglia S, De Luca J $r$ LA \& Menani J V (1992). Role of cholinergic and adrenergic pathways of the medial septal area in the control of water intake and renal excretion in rats. Pharmacology, Biochemistry and Behavior, 42: 1-8.

31. Piletz J E, Ordway GA, Zhu H, Duncan BJ $\&$ Halaris A (2000). Autoradiographic comparison of [3]-clonidine binding to nonadrenergic sites and alpha (2)-adrenergic receptors in human brain. Neuropsychopharmacology, 23: 697-708.

32. Saad WA, Camargo LAA \& Saad WA (1984). Effect of application of alpha-1 and alpha-2 adrenoceptor agonists and antagonists into the ventromedial hypothalamus on the sodium and potassium renal excretion. Pharmacology, 28: 228-234.

33. Arrais CAG, Saad WA, Camargo LAA, Renzi A, Silveira J EN \& Saad R (1997). Effect of rilmenidine injection into the paraventricular nucleus of the hypothalamus on the water intake induced by application of angiotensin II to the subfomical organ. J oumal of Physiology, 91: 97-98.

34. Patel KP \& Zeigler DW (1993). Renal nerves are involved in the natriuresis and diuresis produced by central administration of clonidine in the rat. Proceedings of the Society for Experimental Biology and Medicine, 202: 81-87.

35. Roman R, Cowley AW \& Lechene C (1979). Water diuretic and antidiuretic effect of clonidine in the rat. J ournal of Pharmacology and Experimental Therapeutics, 211: 385-393.

36. Koepke J P \& Dibona GF (1986). Central adrenergic control of renal function in conscious hypertensive rats. Hypertension, 8: 133-141.

37. Saad WA, Camargo PAC \& Camargo LA (1996). On a dual role for clonidine stimulation of the ventromedial nucleus of the hypothalamus in sodium and potassium renal excretion of rats. Pharmacology, 53: 281-288.

38. Silva RKP, Saad WA, Renzi A, Menani J V \& Camargo LAA (1995). Effect of lateral hypothalamus lesion on the water and salt intake and sodium and urine excretion induced by activation of the medium preoptic nucleus in conscious rats. J ournal of the Autonomic Nervous System, 53: 195-204.

39. Saad WA, Camargo LAA, Silveira JEN, Saad WA \& Camargo GMPA (1998). Imidazoline receptors of the paraventricular nucleus on the pressor response induced by stimulation of the subfomical organ. J oumal of Physiology, 92: 25-30.

40. Sy GY, Bruban V, Bousquet $P \&$ Feldman J (2001). Nitric oxide and central antihypertensive drugs: one more difference between catecholamines and imidazolines. Hypertension, 37: 246-249. 